\title{
Mind-Body Practice Is Related to Pro-environmental Engagement Through Self-compassion and Global Identity Rather Than to Self-enhancement
}

\author{
Laura S. Loy ${ }^{1}\left[\right.$ ] Alicia Clemens ${ }^{1} \cdot$ Gerhard Reese $^{1}$ (D)
}

Accepted: 24 December 2021 / Published online: 28 January 2022

(c) The Author(s) 2022

\begin{abstract}
Objectives A recent publication stated that mind-body practices (MBPs) of meditation and yoga boost self-enhancement instead of quieting the ego, contrary to these practices' traditional goals. Surveying practitioners directly after MBP classes or at other time points, the researchers found higher levels of self-esteem and communal narcissism after MBP and interpreted these as indicators of a boosted ego. However, their conceptualization was criticized, and empirical studies on other constructs representing a quiet ego, namely self-compassion and global identity, found that these characteristics were stronger in mind-body practitioners than in non-practitioners and fostered by MBP interventions. This study aimed to bring these research strands together.

Methods Using a preregistered known-groups approach, 211 mind-body practitioners (yoga, meditation, or both) were compared with 190 non-practitioners recruited through a German online panel. The participants answered an online questionnaire assessing self-esteem, communal narcissism, self-compassion, and global identity. Moreover, they reported their pro-environmental behavior and climate policy support.

Results There were no differences regarding self-esteem, and—as only one aspect of communal narcissism-a higher expectation among practitioners that they could positively influence the world. Moreover, they reported higher levels of self-compassion and global identity. MBP was indirectly related to stronger pro-environmental behavior and climate policy support through higher global identity, and partly through higher self-compassion.

Conclusions MBPs might have the potential to contribute to a quiet ego rather than to self-enhancement. Moreover, they might motivate people to engage in societal challenges that go beyond mere self-interest and contribute to a sustainable future.

Study Registration Aspredicted.org: \#44032.
\end{abstract}

Keywords Meditation $\cdot$ Yoga $\cdot$ Quiet ego $\cdot$ Self-compassion $\cdot$ Global identity $\cdot$ Pro-environmental behavior

Gebauer et al. (2018) claimed that the increasingly popular mind-body practices (MBPs) of yoga and meditation "do not quiet the ego but instead boost self-enhancement" (p. 1299). This is undoubtedly a provocative statement because it contradicts one of the main goals formulated in the philosophical origins of MBPs (Levine, 2009). Gebauer et al. (2018) conceptualized a quiet ego as an antidote to an exalted self. They argued that the traditional philosophy behind MBPs

Laura S. Loy

loy@uni-landau.de

1 Department of Social, Environmental and Economic Psychology, Faculty of Psychology, University of KoblenzLandau, Fortstraße 7, 76829 Landau, Germany (see e.g., Levine, 2009) assumes that these practices reduce the importance people attach to their actions and attributes (i.e., self-centrality) and thereby promote accurate self-views instead of exaggerated ones (i.e., self-enhancement bias). On the contrary, the self-enhancement principle proposes that practicing any skill-also MBP-makes the specific skill more self-central, which in turn breeds self-enhancement bias (Gebauer et al., 2017).

To test these contradictory predictions, the researchers investigated 93 yoga practitioners and 162 meditation practitioners in Germany (Gebauer et al., 2018). After MBP and without prior practice, these practitioners reported how central they perceived their MBP (study 1) and related values (study 2) to be, and how they evaluated their own MBP skills (study 1) and related values (study 2) compared to 
those of average practitioners. Moreover, the participants rated their current state of self-esteem and their "narcissistic, self-enhancing tendencies in communal-and, thus, mind-body-relevant-domains" (p. 1301). The researchers found indirect paths from MBP to higher levels of selfenhancement via amplified self-centrality. Self-centrality of the practice and self-enhancement bias represented a boosted ego rather than a quiet one according to Gebauer et al. (2018). Thus, based on their findings, the researchers concluded that MBP promoted self-enhancement bias through augmented self-centrality and did not foster a quiet ego. Recently, Vaughan-Johnston et al. (2021) published a direct replication of Gebauer et al.'s studies in Canadian samples and drew the same conclusions.

Lumma et al. (2020) provided a compelling critique of Gebauer et al.'s conceptualization and assessment of the quiet (or boosted) ego. From a theoretical perspective, Lumma et al. (2020) questioned the conceptualization of the quiet ego as not attaching importance to own actions and attributes. They quoted a common definition that "the quiet ego does not mean a squashed, deflated, or silenced ego. Nor [...] a disregard for one's immediate self-interest" (Wayment \& Bauer, 2018, p. 882), but rather a "self-identity that is neither excessively self-focused nor excessively otherfocused" (Wayment et al., 2015, p. 1000). Moreover, they argued that commitment to and self-care through the MBPand therefore self-centrality-are required in order to quiet the ego according to MBP philosophy. The same applies for compassion towards oneself and others (see Lumma et al., 2020, for details).

Based on these diverging definitions, Lumma et al. (2020) stated that they would not have expected MBP students to score lower on the scales used by Gebauer et al. (2018), for example, regarding the item "I take a positive attitude toward myself" (self-esteem). Furthermore, a person answering an item like "I will be well known for the good deeds I will have done" (communal narcissism) could have either focused on standing out or on the good deed itself. The latter might be more relevant to mind-body practitioners. Apart from these aspects raised by Lumma et al. (2020), answering an item like "In comparison to the average participant of my yoga class, my ability to focus mindfully on the exercises across the whole yoga class is well below/above average" (MBP skills) might have been an irritating experience for practitioners because MBP classes usually explicitly teach them not to judge their own skills and compare them with those of others (i.e., part of cultivating mindfulness-an attentive and non-judgmental awareness for the present moment, Bishop et al., 2004). Lumma et al. (2020) further suspected that the positive effects of MBP on mood might have inflated the self-enhancement measures. Finally, it is likely that using a within-subject design promoted demand effects, in the sense that the participants might have suspected that the researchers expected higher levels in the measures after MBP.

Apart from the fact that Gebauer et al.'s (2018) conclusions are debatable due to the theoretical and methodical reasons outlined above, research assessing alternative indicators for a quiet ego found that these indicators were fostered by MBP interventions and higher in practitioners compared to non-practitioners. First, it needs to be noted that "the (quiet) ego" is not a concise and unequivocal concept, but rather an umbrella term. Several psychological constructs have been discussed as representing a quiet ego. These constructs either understand the ego as evaluations of the self or as identities that relate to, include, or exclude others (see Bauer \& Wayment, 2008, for a more detailed categorization and an overview). Two concrete examples are self-evaluation in the form of self-compassion and identification in the form of global identity.

Self-compassion is defined as "being touched by one's own suffering, generating the desire to alleviate one's suffering and treat oneself with understanding and concern" (Neff \& Germer, 2013, p. 28). Neff (2008) described it as a healthier alternative to strong self-esteem (i.e., "how much one likes or values the self [...] based on congruence with personal standards or on comparisons with others", p. 96). The construct thus seems interesting when critically examining the propositions made by Gebauer et al. (2018). Researchers have argued that self-compassion might be fostered by MBPs because it involves being aware of painful thoughts and feelings without over-identifying with them and is thus conceptually linked to MBP's primary outcome, which is mindfulness (see, e.g., Birnie et al., 2010). Supporting this assumption, Neff and Germer (2013) reported on a MBP program that increased self-compassion (see also Birnie et al., 2010; Gorvine et al., 2019). Mind-body practitioners reported stronger self-compassion than non-practitioners in a study by Gu et al. (2020).

Global identity means identification with and concern for all humanity (see McFarland et al., 2012, 2019). It has been argued that MBPs might have the potential to cultivate global identity because compassion for and connectedness with all humans is a traditional goal of MBPs (see Loy \& Reese, 2019, for further details). Indeed, Brito-Pons et al. (2018) found that a MBP training program focusing on cultivating compassion increased not only self-compassion but also global identity. A study comparing mind-body practitioners with non-practitioners revealed higher levels of global identity in practitioners (Loy \& Reese, 2019).

In addition to cultivating a quiet ego, MBP has been discussed as a possible means of encouraging pro-environmental engagement (e.g., pro-environmental behavior, climate policy support; see Loy \& Reese, 2019; Panno et al., 2017), which can be regarded as a pro-social tendency that goes beyond mere self-interest (Kaiser \& Byrka, 2011; Klein 
et al., 2021; Otto et al., 2021). A large body of research has aimed to explain and promote pro-environmental engagement in the face of the urgent current environmental crises (see, e.g., Fritsche et al., 2018; Klöckner, 2013, for overviews that integrate relevant theories and empirical findings). Many factors play a role for pro-environmental engagement, and researchers have reasoned that MBP might be a means of cultivating relevant individual characteristics (e.g., Stanszus et al., 2017; Thiermann \& Sheate, 2020). Even though causal evidence is still lacking (Geiger et al., 2019), MBP practitioners have reported stronger pro-environmental behavior and climate policy support compared to non-practitioners in known-groups studies (Loy \& Reese, 2019; Panno et al., 2017). These relations were partly explained by higher levels of global identity (Loy \& Reese, 2019). Hence, a quieter ego might be a mechanism through which MBP could encourage pro-environmental engagement.

Researchers have argued that identification with all humanity might be a pathway towards addressing global (and socially unjust) environmental threats such as climate change because people strive for the well-being of their ingroups (e.g., Reese, 2016). Indeed, several prior studies have shown that global identity is positively related to proenvironmental behavior and policy support (e.g., Joanes, 2019; Loy \& Reese, 2019; Loy et al., 2021; Renger \& Reese, 2017).

The quiet ego component self-compassion has not been examined in relation to pro-environmental engagement yet. On the one hand, self-compassion-as an indicator of well-being-might allow people to invest their resources in efforts beyond their self-interest. In line with this thought, a review by Lyubomirsky et al. (2005) showed that well-being is related to community involvement and diverse pro-social behaviors. Kasser (2017) argued that pro-environmental engagement often involves pro-sociality and helping, and therefore well-being might encourage pro-environmental engagement. Accordingly, several scholars have theorized well-being as a mechanism that explains a relation between mindfulness (or MBP) and pro-environmental engagement (e.g., Geiger et al., 2019; Thiermann \& Sheate, 2020). On the other hand, self-compassion could be linked to pro-environmental engagement via compassion for others. Indeed, self-compassion correlated positively with compassion for others ( $\mathrm{Gu}$ et al., 2020), and compassion for others, in turn, correlated positively with pro-environmental behavioral intentions (Pfattheicher et al., 2015).

When it comes to the ego characteristics that stand for a boosted ego according to Gebauer et al. (2018), a positive relation between self-esteem and pro-environmental engagement has been theorized but not empirically found yet (Allen \& Ferrand, 1999). Research by Naderi (2018) suggested that communal narcissism is positively related to pro-environmental behavior, but only if it is perceived by others or does not involve self-sacrifice. Hence, it remains unclear as to whether a boosted ego as defined by Gebauer et al. (2018) is related to pro-environmental engagement.

The present study brought together these two research strands and assessed both the constructs representing a boosted ego according to Gebauer et al. (2018) and the constructs representing a quiet ego. A known-groups approach instead of a within-subject design was used to compare mind-body practitioners and non-practitioners regarding their self-esteem, communal narcissism, self-compassion, and global identity. Moreover, the scope of previous studies was extended by investigating the potential role of MBP and the abovementioned ego components for encouraging proenvironmental engagement. Thereby, this study additionally aimed to contribute to the urgent search for ways of promoting socio-ecological societal change.

The outlined theoretical considerations and empirical evidence led to the following hypotheses $(\mathrm{H})$ : Mind-body practitioners have either stronger (H1.1) or weaker (H1.2) self-esteem and communal narcissism than non-practitioners (competing hypotheses; due to the use of known-groups instead of within-subject comparisons, evaluation of MBP skills was not examined). Mind-body practitioners have stronger self-compassion and global identity than non-practitioners (H2). The stronger people's self-compassion and global identity, the stronger their pro-environmental engagement (pro-environmental behavior, climate policy support; H3). Mind-body practitioners show more pro-environmental engagement compared to non-practitioners (H4), and mind-body practice indirectly predicts pro-environmental engagement through stronger self-compassion and global identity (H5). Due to the lack of a research basis, open research questions (RQs) were asked to determine whether self-esteem and communal narcissism are related to proenvironmental engagement (RQ1), and whether mind-body practice indirectly predicts pro-environmental engagement through weaker or stronger self-esteem and communal narcissism (RQ2).

\section{Method}

\section{Participants}

We conducted an a priori power analysis using the Shiny App (Schoemann et al., 2017). We aimed for a test power of .80 and based effect size estimates on prior research (Gebauer et al., 2018; Loy \& Reese, 2019; Marshall et al., 2015; Naderi, 2018). The Shiny App, which is limited to models with two mediators, suggested a sample of $N=321$. We aspired to an extended sample size of $N=400$ (see Supplementary Materials, Section A, for further details). 
Sixteen participants were excluded because they asked for their data to be deleted, two because they did not answer the attention check question correctly (i.e., "In order to show us that you are answering attentively, please click 'often'," embedded in the pro-environmental behavior measure), and nine were classified as speeders (i.e., relative speed index $\geq 2.0$, see Leiner, 2019). Thus, the final sample consisted of $N=401$ participants (286 women, 113 men, 2 diverse; $M=42.5$ years of age, $S D=15.6$, range 18-82; see Supplementary Materials, Section B, for further details): 211 of them were mind-body practitioners (65 yoga only, 71 meditation only, 75 both); 190 practiced neither meditation nor yoga. We compared the practitioners to the non-practitioners. The groups did not differ regarding age $(t(399)=1.42, p=.155)$. However, the proportion of males was lower among practitioners $(18.5 \%)$ compared to nonpractitioners $\left(39.4 \% ; \chi^{2}(1)=21.35, p<.001\right.$; we excluded the $n=2$ people indicating themselves as diverse from this analysis).

\section{Procedures}

The study was approved by the university's local ethics committee and underwent a review process in order to be conducted using the German SoSci Panel (www.sosci panel.de). This non-commercial panel originates from a university project and draws on a convenience pool of more than 80,000 participants who support interesting research. The study was preregistered (https://aspredicted. org/tq8gr.pdf). The data were collected using the software SoSci Survey (www.soscisurvey.de) in July 2020. The data set and syntax are available on the OSF Forum (https:// osf.io/6n2tb/). A raffle of four $€ 25$ vouchers for an online store served as an incentive. The participants gave their informed consent.

\section{Measures}

We used established measures to assess the constructs of interest and standardized some of the answer scales to ease the flow for participants and because 7-point scales are supposedly preferable to 5-point scales (Krosnick \& Presser, 2010). The measures and their psychometric properties are summarized in Table 1.

\section{Mind-Body Practice}

The participants stated whether they practice yoga (yes, no) and meditation (yes, no). We used the dichotomous variable MBP for our analyses: 0 (none) and 1 (yoga, meditation, or both). Furthermore, participants with MBP practice stated how long they had been practicing (yoga: $n=138$ (2 missings), $M=80$ months, $S D=100$; meditation: $n=142$ (4 missings), $M=111$ months, $S D=129)$ and how much time they spent practicing per week (yoga: $n=137$ (3 missings), $M=131$ min, $S D=228$; meditation: $n=142$ (4 missings), $M=153 \mathrm{~min}, S D=386$; see Loy \& Reese, 2019).
Table 1 Psychometric properties of the measures

\begin{tabular}{llllllllll}
\hline Variable & $n$ & $M$ & $S D$ & Range & Items & $\alpha$ & $\omega$ & AVE & $R_{P}$ \\
\hline Self-esteem & 399 & 5.31 & 1.17 & 1.40 to 7.00 & 10 & .93 & .94 & .66 & - \\
$\quad$ Positive & 400 & 5.45 & 1.03 & 1.40 to 7.00 & 5 & .87 & .88 & .60 & - \\
$\quad$ Negative (recoded) & 400 & 5.18 & 1.45 & 1.00 to 7.00 & 5 & .91 & .91 & .69 & - \\
Communal narcissism & 397 & 3.65 & 0.97 & 1.00 to 6.23 & $13^{\text {b }}$ & .90 & .92 & .55 & - \\
$\quad$ World influence & 398 & 2.87 & 1.25 & 1.00 to 6.29 & 7 & .91 & .92 & .61 & - \\
$\quad$ Personal relations & 398 & 4.55 & 0.97 & 1.00 to 6.67 & 6 & .82 & .83 & .45 & - \\
Self-compassion & 400 & 4.66 & 0.78 & 2.27 to 6.45 & $11^{\text {c }}$ & .86 & .89 & .47 & - \\
$\quad$ Positive & 400 & 4.65 & 0.86 & 2.20 to 6.60 & $5^{\text {c }}$ & .73 & .74 & .37 & - \\
$\quad$ Negative (recoded) & 400 & 4.30 & 1.19 & 1.17 to 6.83 & 6 & .86 & .87 & .53 & - \\
Global identity & 399 & 4.87 & 1.27 & 1.30 to 7.00 & 10 & .93 & .94 & .64 & - \\
$\quad$ Self-definition & 401 & 4.68 & 1.39 & 1.00 to 7.00 & 5 & .90 & .90 & .65 & - \\
$\quad$ Self-investment & 399 & 5.06 & 1.28 & 1.00 to 7.00 & 5 & .89 & .89 & .62 & - \\
Pro-environmental behavior & 401 & 0.22 & 1.09 & -5.01 to 3.69 & 34 & .82 & - & - & .82 \\
Climate policy support & 397 & 5.40 & 1.12 & 1.30 to 7.00 & 10 & .88 & .91 & .58 & - \\
$\quad$ Restrict fossil energy & 400 & 5.04 & 1.59 & 1.00 to 7.00 & 3 & .86 & .87 & .68 & - \\
$\quad$ Restrict flight mobility & 398 & 4.86 & 1.61 & 1.00 to 7.00 & 3 & .77 & .77 & .53 & - \\
$\quad$ Pull measures & 399 & 6.09 & 0.95 & 1.00 to 7.00 & 4 & .79 & .79 & .50 & - \\
\hline
\end{tabular}

Note. ${ }^{\text {a }}$ Results are based on Rasch analysis. ${ }^{\mathrm{b}}$ Three items excluded based on factor analyses. ${ }^{\mathrm{c}}$ One item excluded based on factor analyses. $\alpha=$ Cronbach's alpha, $\omega=$ coefficient omega, AVE=average variance extracted, $R_{P}=$ person separation reliability based on Rasch model 


\section{Self-esteem}

We used a German version of Rosenberg's Self-Esteem Scale (Collani \& Herzberg, 2003; original by Rosenberg, 1965). The participants rated 10 statements with scale points ranging from 1 (doesn't apply at all) to 7 (fully applies). The confirmatory factor analysis (CFA) of a one-dimensional model did not yield a satisfactory model fit, $\chi^{2}(35)=304.19$, $p<.001 ; \mathrm{CFI}=.87 ; \mathrm{TLI}=.83 ; \mathrm{RMSEA}=.139,90 \% \mathrm{CI}[.126$, .152]; SRMR $=.065$. However, a two-dimensional model with correlating factors differentiating between (1) positively formulated items (e.g., "On the whole, I am satisfied with myself") and (2) recoded negatively formulated items (e.g., "At times I think I am no good at all") fitted the data well, except for RMSEA which slightly exceeded the threshold of $.08, \chi^{2}(34)=140.33, p<.001 ; \mathrm{CFI}=.95 ; \mathrm{TLI}=.93$; RMSEA $=.089,90 \%$ CI $[.075, .103]$; SRMR $=.049$. The standardized factor loadings were between .63 and .91 . The two dimensions correlated with $r=.84$.

\section{Communal Narcissism}

We used the German version of the Communal Narcissism Inventory (Gebauer et al., 2012). The participants rated 16 statements with scale points ranging from 1 (doesn't apply at all) to 7 (fully applies). The CFA of a one-dimensional model did not yield a satisfactory model fit, $\chi^{2}(104)=722.74, p<.001 ; \mathrm{CFI}=.76 ; \mathrm{TLI}=.73$; $\mathrm{RMSEA}=.123,90 \%$ CI $[.115, .131]$; $\mathrm{SRMR}=.102$. Therefore, we conducted an exploratory factor analysis (EFA) to examine the underlying structure. The Kaiser-Meyer-Olkin coefficients were between .88 and .96, and the items were hence well suited. A parallel analysis suggested three factors. We conducted a respective principal axis factor analysis with promax rotation. However, as the third factor consisted of only two items, we conducted a second analysis on a two-factor solution (TLI $=.91$, RMSEA $=.076,90 \%$ CI $[.065, .084])$. It suggested two dimensions which can be interpreted as (1) narcissism regarding world influence (items 2, 4, 7, 9, 11, 14, 16; e.g., "In the future, I will be well-known for solving the world's problems") and (2) narcissism regarding personal relations (items 1, 3, 6, 10, 13, 15; e.g., "I' $m$ the most caring person in my social surrounding"). We excluded three items with substantial cross-loadings (items 5, 8, 12; see Supplementary Materials, Section C, for further details). A CFA for a respective two-dimensional model with correlating factors yielded a satisfactory model fit, $\chi^{2}(64)=148.48$, $p<.001 ; \mathrm{CFI}=.96 ; \mathrm{TLI}=.95 ; \mathrm{RMSEA}=.058,90 \% \mathrm{CI}$ $[.046, .069] ;$ SRMR $=.044$. The standardized factor loadings were between .53 and .84 . The two dimensions correlated with $r=.54$.

\section{Self-compassion}

We used the German short version of the Self-Compassion Scale (Hupfeld \& Ruffieux, 2011; English version by Raes et al., 2011). The participants rated 12 statements with scale points ranging from 1 (never) to 7 (always). The CFA of a one-dimensional model did not yield a satisfactory model fit, $\chi^{2}(54)=279.72, p<.001 ; \mathrm{CFI}=.82 ; \mathrm{TLI}=.79$; RMSEA $=.102,90 \%$ CI $[.092, .113]$; SRMR $=.084$. However, a two-dimensional model differentiating between (1) positively formulated items (e.g., "I try to see my failings as part of the human condition"; excluding Item 10 due to a low factor loading of .36) and (2) recoded negatively formulated items (e.g., "I'm disapproving and judgmental about my own flaws and inadequacies") fitted the data well, $\chi^{2}(43)=93.54$, $p<.001 ; \mathrm{CFI}=.96 ; \mathrm{TLI}=.95 ; \mathrm{RMSEA}=.054,90 \% \mathrm{CI}$ $[.040, .068] ; \mathrm{SRMR}=.042$. The standardized factor loadings were between .50 and .80 . The two dimensions correlated with $r=.67$.

\section{Global Identity}

We used a German adapted version (Loy \& Reese, 2019) of the Identification with all Humanity Scale (McFarland et al., 2012; Reese et al., 2015). The participants rated 10 statements with scale points ranging from 1 (doesn't apply at all) to 7 (fully applies). The scale comprises the dimensions of global self-definition (i.e., identification as part of all humanity; e.g., "I think of people all over the world as 'we' ") and self-investment (i.e., solidarity with and care for people all over the world; e.g., "I want to help people all over the world"). The CFA of the two-dimensional model (see Hamer et al., 2021; Reese et al., 2015; Reysen \& Hackett, 2016) with correlating factors yielded a satisfactory model fit, $\chi^{2}(34)=82.50, p<.001 ; \mathrm{CFI}=.97$; TLI $=.96$; RMSEA $=.060,90 \%$ CI [.046, .073]; SRMR $=.032$. The standardized factor loadings were between .67 and .86 . The two dimensions correlated with $r=.90$. A one-dimensional model yielded a less satisfactory model fit, $\chi^{2}(35)=136.01$, $p<.001 ; \mathrm{CFI}=.94 ; \mathrm{TLI}=.93 ; \mathrm{RMSEA}=.085,90 \% \mathrm{CI}$ $[.073, .097] ; \mathrm{SRMR}=.043 ; \chi_{\text {diff }}^{2}(1)=41.73, p<.001$.

\section{Pro-environmental Behavior}

We used an adapted 34-item version of the General Ecological Behavior Scale (Kaiser \& Wilson, 2000, 2004). The participants rated how often they engaged in 28 behaviors with scale points ranging from 1 (never) to 5 (very often; e.g., "I refrain from eating meat") and whether they engaged in six further behaviors (yes, no; e.g., "I get green electricity”). Following Kaiser and Wilson (2000, 2004), we applied Rasch modelling (see Bond \& Fox, 2007). As recommended, we dichotomized the items as 0 (never, seldom, once in a 
while; no) or 1 (often, very often; yes) for pro-environmental behaviors and as 0 (once in a while, often, very often; yes) or 1 (never, seldom; no) for anti-environmental behaviors (see Kaiser \& Wilson, 2000, 2004, for the detailed reasoning). We provided the answer option cannot answer for behaviors not applicable to people's living situation, as missing data can be handled by Rasch models. The item mean square infit values were below the threshold of 1.30 recommended for samples smaller than 500, except for one item which had a slightly higher infit of 1.31. As the deviation was minimal, we kept the item in the scale. Person $t$ infit values above 1.96 indicated that the model did not fit the data of only six $(1.5 \%)$ participants well; this was hence under the recommended threshold of $5 \%$.

\section{Climate Policy Support}

We reworked a measure for assessing Climate Policy Support used by Loy and Reese (2019). The participants rated 10 policy measures with scale points ranging from 1 (fully against) to 7 (fully in favor). Three items covered the subordinate dimension of restricting fossil energy (e.g., " $\mathrm{CO}_{2}$ pricing for fossil fuels [oil, gas, coal]"); three addressed restricting flight mobility (e.g., "prohibition of private inland flights below 1,000 km"), and four covered supportive pull measures (e.g., "using public money to invest in urban green areas"). A CFA for a three-dimensional model with a superordinate factor yielded a satisfactory model fit, $\chi^{2}(32)=99.80, p<.001 ; \mathrm{CFI}=.95$; TLI $=.93$; RMSEA $=.073,90 \%$ CI $[.059, .088]$; SRMR $=.053$. The standardized factor loadings were between .69 and .92 .

\section{Data Analyses}

We used the statistical environment $R$ for our analyses. To examine the scales, we conducted Rasch modelling, EFA, and CFA. As Shapiro tests indicated non-normality, we applied robust maximum likelihood estimation to the latter. To compare mind-body practitioners with non-practitioners $(\mathrm{H} 1, \mathrm{H} 2, \mathrm{H} 4)$, we conducted $t$ tests; to test relations between the ego components and pro-environmental engagement (H3, RQ1), we calculated Pearson correlations. Even though rules of thumb for effect size evaluation are criticizable (Funder \& Ozer 2019), we used Cohen's (1992) suggestions as a rough guideline and interpreted the effect size Cohen's $d=0.20$ as small, $d=0.50$ as medium, $d=0.80$ as large, and the Pearson's correlation coefficients of $r=.10$ as small, $r=.30$ as medium, and $r=.50$ as large. In order to test the indirect relations between MBP and pro-environmental engagement through the ego components (H5 and RQ2), we calculated structural equation models (SEMs), modeling the constructs as latent variables. We applied robust maximum likelihood estimation and tested relations for significance by applying bootstrapped confidence intervals with 1,000 samples.

\section{Results}

\section{Comparison of Mind-Body Practitioners and Non-practitioners}

Table 2 shows that the mind-body practitioners in our sample did not differ in their self-esteem from non-practitioners, thus not supporting the competing hypotheses that they have higher self-esteem (H1.1) or lower self-esteem (H1.2). However, mind-body practitioners reported stronger communal narcissism compared to non-practitioners, in the sense that they expected to have a stronger influence in the world (small difference of $d=0.25, p=0.012$ ). They did not differ regarding their evaluation of their role in personal relationships as extraordinary. Hence, this result partly supports H1.1. In line with $\mathrm{H} 2$, the mind-body practitioners reported stronger self-compassion than non-practitioners based on the positively formulated items (medium difference of $d=0.52$, $p<0.001)$. Moreover, they also expressed a stronger global identity regarding both dimensions of global self-definition (small difference of $d=0.35, p<0.001$ ) and self-investment (small difference of $d=0.24, p=0.018$ ). Supporting H4, the mind-body practitioners reported more pro-environmental behavior (medium difference of $d=0.54, p<0.001$ ) and climate policy support ( small difference of $d=0.27, p=0.007$ ) compared to the non-practitioners.

\section{Relations Between Ego Components and Pro-environmental Engagement}

The bivariate correlations between the mean scores of all assessed variables can be found in the Supplementary Materials, Section D. The variance inflation factors (VIF) were $\leq 3.52$, and the tolerance values $1 / \mathrm{VIF} \geq 0.74$, indicating no multicollinearity.

The participants' self-compassion captured by the positively formulated items significantly correlated with their self-reported pro-environmental behavior (small correlation of $r=.20, p<.001$ ), but not with their climate policy support. There was even a small negative relation between the recoded negatively formulated self-compassion items and policy support $(r=-.11, p=.022)$. Both global selfdefinition and self-investment were positively related to proenvironmental behavior ( $r=.37$ and $r=.39$, respectively) and climate policy support $(r=.40, r=.44$, respectively, all $p s<.001$, medium correlations). Hence, $\mathrm{H} 3$ was fully supported with regard to global identity but only partly with regard to self-compassion. 
Table 2 Variables differentiated for mind-body practitioners and non-practitioners

\begin{tabular}{|c|c|c|c|c|c|c|c|c|}
\hline \multirow[b]{2}{*}{ Variable } & \multicolumn{2}{|c|}{$\begin{array}{l}\text { Practitioners } \\
(n=211)\end{array}$} & \multicolumn{2}{|c|}{$\begin{array}{l}\text { Non-practi- } \\
\text { tioners } \\
(n=190)\end{array}$} & \multirow[b]{2}{*}{$95 \% \mathrm{CI}$} & \multirow[b]{2}{*}{$t$} & \multirow[b]{2}{*}{$p$} & \multirow[b]{2}{*}{$d$} \\
\hline & $M$ & $S D$ & $M$ & $S D$ & & & & \\
\hline Self-esteem & 5.37 & 1.13 & 5.25 & 1.20 & {$[-0.36,0.10]$} & -1.09 & .277 & 0.11 \\
\hline Positive & 5.54 & 0.96 & 5.35 & 1.10 & {$[-0.40,0.00]$} & -1.92 & .055 & 0.19 \\
\hline Negative (recoded) & 5.20 & 1.43 & 5.15 & 1.48 & {$[-0.34,0.23]$} & -0.36 & .718 & 0.04 \\
\hline Communal narcissism & 3.76 & 0.97 & 3.53 & 0.96 & {$[-0.42,-0.04]$} & -2.36 & .019 & $0.24 *$ \\
\hline World influence & 3.01 & 1.25 & 2.70 & 1.22 & {$[-0.56,-0.07]$} & -2.53 & .012 & $0.25 *$ \\
\hline Personal relations & 4.62 & 0.94 & 4.48 & 1.01 & {$[-0.33,0.05]$} & -1.46 & .145 & 0.15 \\
\hline Self-compassion & 4.56 & 0.93 & 4.34 & 0.89 & {$[-0.39,-0.03]$} & -2.31 & .021 & $0.23 *$ \\
\hline Positive & 4.85 & 0.82 & 4.42 & 0.84 & {$[-0.60,-0.27]$} & -5.19 & $<.001$ & $0.52 *$ \\
\hline Negative (recoded) & 4.31 & 1.21 & 4.28 & 1.17 & {$[-0.26,0.20]$} & -0.26 & .795 & 0.03 \\
\hline Global identity & 5.06 & 1.21 & 4.67 & 1.30 & {$[-0.64,-0.15]$} & -3.13 & .002 & $0.31 *$ \\
\hline Self-definition & 4.91 & 1.35 & 4.43 & 1.39 & {$[-0.75,-0.21]$} & -3.52 & $<.001$ & $\mathbf{0 . 3 5} *$ \\
\hline Self-investment & 5.20 & 1.21 & 4.90 & 1.34 & {$[-0.55,-0.05]$} & -2.38 & .018 & $0.24 *$ \\
\hline Pro-environmental behavior ${ }^{\mathrm{a}}$ & 0.49 & 1.08 & -0.08 & 1.02 & {$[-0.78,-0.36]$} & -5.41 & $<.001$ & $0.54 *$ \\
\hline Climate policy support & 5.54 & 1.09 & 5.24 & 1.12 & {$[-0.52,-0.08]$} & -2.71 & .007 & $0.27 *$ \\
\hline Restrict fossil energy & 5.20 & 1.60 & 4.85 & 1.57 & {$[-0.66,-0.04]$} & -2.20 & .029 & $0.22 *$ \\
\hline Restrict flight mobility & 5.05 & 1.59 & 4.66 & 1.61 & {$[-0.71,-0.07]$} & -2.43 & .016 & $0.24 *$ \\
\hline Pull measures & 6.19 & 0.90 & 5.97 & 0.99 & {$[-0.41,-0.04]$} & -2.35 & .019 & $0.24 *$ \\
\hline
\end{tabular}

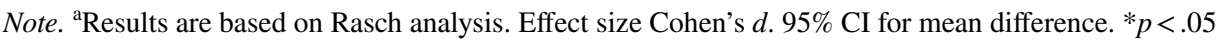

Answering RQ1, we found no correlation between selfesteem and pro-environmental behavior, a small negative correlation between the negatively formulated self-esteem items and policy support $(r=-.15, p=.003)$, no correlation between communal narcissism regarding personal relations and either pro-environmental behavior or policy support, but small positive correlations between communal narcissism regarding world influence and pro-environmental behavior $(r=.18, p<.001)$ as well as climate policy support $(r=.13$, $p=.009)$.

\section{Indirect Relations Between MBP and Pro-environmental Engagement Through the Ego Components}

Due to the many interrelated facets and resulting complexity, we first defined eight separate mediation models for each dimension of each ego component, with MBP as the dichotomous predictor, the respective ego component as the mediator, and pro-environmental behavior (Rasch score) and climate policy support as the outcomes (see Supplementary Materials, Section E, for detailed results).

We found that MBP was indirectly related to more proenvironmental behavior through higher self-compassion (dimension consisting of positive items only, $\beta=.05$, $p=.007)$, global self-definition ( $\beta=.07, p=.002)$, and global self-investment $(\beta=.05, p=.022)$. MBP was indirectly related to more climate policy support through higher global self-definition $(\beta=.09, p=.002)$ and global self-investment ( $\beta=.07, p=.022)$, but not through self-compassion. Hence, H5 was supported for global identity and partly also for selfcompassion. However, the indirect relations were small. Answering RQ2, we found no indirect relations between MPB and either pro-environmental behavior or policy support through the dimensions of either self-esteem or communal narcissism.

In a next step, we aimed to find out whether either self-compassion or global identity was the more relevant mediator. Therefore, we specified two parallel mediation models including the positively formulated dimension of self-compassion and either global self-definition (model A) or global self-investment (model B) as mediators (see Fig. 1 and Tables 3 and 4). We did not include both global identity dimensions simultaneously because they correlated very strongly $(r=.90)$, which would have posed a problem of collinearity.

The analysis of model A revealed that when self-compassion and global self-definition were regarded simultaneously, only global self-definition mediated the relation between MBP and pro-environmental behavior (indirect relation: $\beta=.06, p=.002$ ) and climate policy support (indirect relation: $\beta=.09, p=.002$ ), while self-compassion did not mediate the relation (indirect relations pro-environmental behavior: $\beta=.02, p=.274$; climate policy support: $\beta=-.03, p=.258$ ). The analysis of model $\mathrm{B}$ revealed that when self-compassion and global self-investment were 

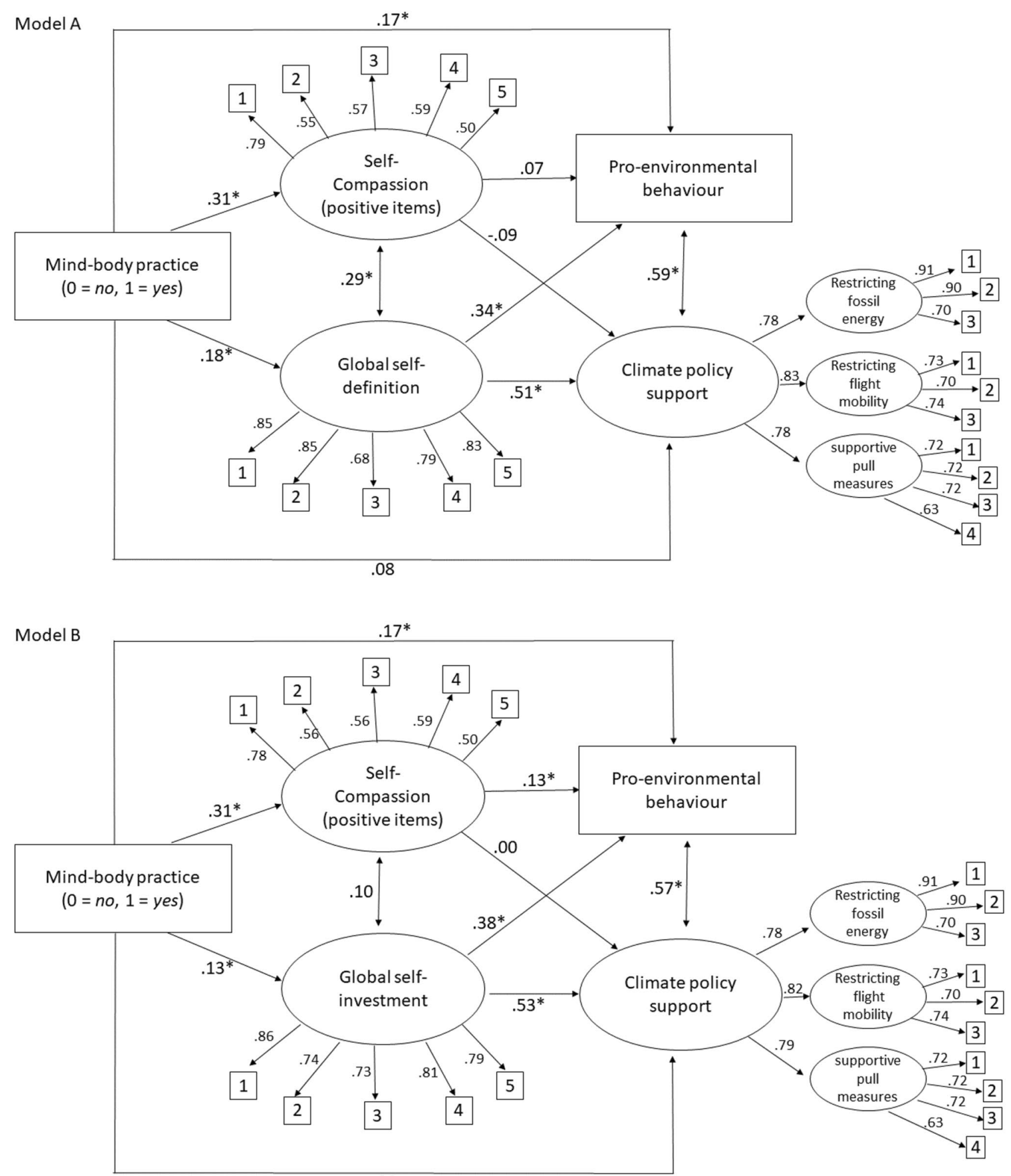

.08

Fig. 1 Structural equation models examining the indirect relation between mind-body practice and pro-environmental engagement through self-compassion and the dimensions of global identity-selfdefinition (model A) and self-investment (model B). Standardized coefficients are displayed. The relations between self-compassion and global self-definition/self-investment, and between pro-environmental behavior and climate policy support represent residual correlations. Correlations between the dimensions of policy support are not displayed to enhance readability. Pro-environmental behavior is represented by Rasch scores 
Table 3 Results of the structural equation model for self-compassion (positive items) and global self-definition as parallel mediators

\begin{tabular}{|c|c|c|c|c|c|c|}
\hline & Path & $B$ & $S E$ & $p$ & $95 \% \mathrm{CI}$ & $\beta$ \\
\hline & \multicolumn{6}{|l|}{$\begin{array}{l}\text { Model A (global self-definition): } \chi^{2}(198)=360.78, p<.001 ; \mathrm{CFI}=.95 \\
\text { TLI }=.94 ; \text { RMSEA }=.046,90 \% \text { CI }[.038, .053] ; \mathrm{SRMR}=.052\end{array}$} \\
\hline $\mathrm{H} 2$ & Direct relation practice—self-compassion & 0.60 & 0.12 & $<.001$ & {$[0.37,0.82]$} & $.31 *$ \\
\hline $\mathrm{H} 2$ & Direct relation practice-global self-definition & 0.51 & 0.16 & .001 & {$[0.20,0.81]$} & $.18 *$ \\
\hline H3 & Direct relation self-compassion-pro-environmental behavior & 0.08 & 0.07 & .271 & {$[-0.06,0.21]$} & .07 \\
\hline $\mathrm{H} 3$ & Direct relation global self-definition-pro-environmental behavior & 0.26 & 0.04 & $<.001$ & {$[0.18,0.34]$} & $.34 *$ \\
\hline $\mathrm{H} 3$ & Direct relation self-compassion—climate policy support & -0.11 & 0.10 & .255 & {$[-0.31,0.08]$} & -.09 \\
\hline H3 & Direct relation global self-definition—climate policy support & 0.43 & 0.07 & $<.001$ & {$[0.30,0.56]$} & $.51 *$ \\
\hline \multirow[t]{2}{*}{$\mathrm{H} 4$} & Direct relation practice-pro-environmental behavior & 0.38 & 0.10 & $<.001$ & {$[0.17,0.58]$} & $.17 *$ \\
\hline & Total relation practice-pro-environmental behavior & 0.55 & 0.11 & $<.001$ & {$[0.35,0.76]$} & $.25^{*}$ \\
\hline \multirow[t]{2}{*}{ H4 } & Direct relation practice—climate policy support & 0.20 & 0.14 & .161 & {$[-0.08,0.47]$} & .08 \\
\hline & Total relation practice-climate policy support & 0.35 & 0.14 & .012 & {$[0.08,0.61]$} & $.14 *$ \\
\hline H5 & Indirect relation practice—-self-compassion-pro-environmental behavior & 0.05 & 0.04 & .274 & {$[-0.04,0.13]$} & .02 \\
\hline H5 & Indirect relation practice—global self-definition—pro-environmental behavior & 0.13 & 0.04 & .002 & {$[0.05,0.22]$} & $.06 *$ \\
\hline H5 & Indirect relation practice—self-compassion—climate policy support & -0.07 & 0.06 & .258 & {$[-0.19,0.05]$} & -.03 \\
\hline H5 & Indirect relation practice—global self-definition—climate policy support & 0.22 & 0.07 & .002 & {$[0.08,0.36]$} & $.09 *$ \\
\hline
\end{tabular}

Table 4 Results of the structural equation model for self-compassion (positive items) and global self-investment as parallel mediators

\begin{tabular}{|c|c|c|c|c|c|c|}
\hline & Path & $B$ & $S E$ & $p$ & $95 \% \mathrm{CI}$ & $\beta$ \\
\hline & \multicolumn{6}{|l|}{$\begin{array}{l}\text { Model B (global self-investment) }: \chi^{2}(198)=387.07, p<.001 ; \mathrm{CFI}=.94 ; \mathrm{TLI}=.93 \\
\text { RMSEA }=.049,90 \% \text { CI }[.042, .056] ; \mathrm{SRMR}=.055\end{array}$} \\
\hline $\mathrm{H} 2$ & Direct relation practice—self-compassion & 0.60 & 0.12 & $<.001$ & {$[0.37,0.83]$} & $.31 *$ \\
\hline $\mathrm{H} 2$ & Direct relation practice_-global self-investment & 0.35 & 0.15 & .018 & {$[0.06,0.64]$} & $.13^{*}$ \\
\hline H3 & Direct relation self-compassion-pro-environmental behavior & 0.15 & 0.06 & .019 & {$[0.02,0.28]$} & $.13 *$ \\
\hline H3 & Direct relation global self-investment—pro-environmental behavior & 0.29 & 0.04 & $<.001$ & {$[0.22,0.37]$} & $.38^{*}$ \\
\hline $\mathrm{H} 3$ & Direct relation self-compassion—climate policy support & 0.00 & 0.09 & .964 & {$[-0.17,0.17]$} & .00 \\
\hline H3 & Direct relation global self-investment—climate policy support & 0.46 & 0.06 & $<.001$ & {$[0.33,0.57]$} & $.53 *$ \\
\hline \multirow[t]{2}{*}{ H4 } & Direct relation practice—-pro-environmental behavior & 0.36 & 0.10 & $<.001$ & {$[0.16,0.56]$} & $.17 *$ \\
\hline & Total relation practice-pro-environmental behavior & 0.55 & 0.11 & $<.001$ & {$[0.35,0.76]$} & $.25 *$ \\
\hline \multirow[t]{2}{*}{$\mathrm{H} 4$} & Direct relation practice—climate policy support & 0.19 & 0.13 & .150 & {$[-0.07,0.46]$} & .08 \\
\hline & Total relation practice—climate policy support & 0.36 & 0.14 & .010 & {$[0.09,0.62]$} & $.15^{*}$ \\
\hline H5 & Indirect relation practice—-self-compassion—pro-environmental behavior & 0.09 & 0.04 & .028 & {$[0.01,0.17]$} & $.04 *$ \\
\hline H5 & Indirect relation practice_-global self-investment- - pro-environmental behavior & 0.10 & 0.05 & .025 & {$[0.01,0.19]$} & $.05^{*}$ \\
\hline H5 & Indirect relation practice—self-compassion—climate policy support & 0.00 & 0.05 & .964 & {$[-0.10,0.10]$} & .00 \\
\hline H5 & Indirect relation practice—global self-investment—climate policy support & 0.16 & 0.07 & .025 & {$[0.02,0.30]$} & $.07 *$ \\
\hline
\end{tabular}

regarded simultaneously, both global self-investment (indirect relation: $\beta=.05, p=.025$ ) and self-compassion (indirect relation: $\beta=.04, p=.028$ ) mediated the relation between MBP and pro-environmental behavior. Global self-investment mediated the relation between MBP and climate policy support (indirect relation: $\beta=.07, p=.025$ ), while self-compassion did not mediate the relation (indirect relation: $\beta=.00, p=.964)$. Again, all indirect relations were small.

In an additional analysis, we controlled for gender and age in both models (see Supplementary Materials,
Section F, for details). Age was related to self-compassion $(\beta=.19, p=.001)$, and female gender was related to global self-definition $(\beta=.15, p=.006)$ and self-investment $(\beta=.16, p=.005)$. In model $\mathrm{A}$, the results changed only slightly with regard to the exact coefficients. However, in model B, the direct relation between MBP and global self-investment was insignificant, which led to insignificant indirect relations between MBP and proenvironmental engagement $(\beta=.03, p=.096)$ and climate policy support $(\beta=.05, p=.098)$ through global self-investment. 


\section{Discussion}

While Gebauer et al. (2018) found that people reported higher self-esteem and communal narcissism after practicing meditation or yoga compared to other time points, our results only provide partial support for their supposition that MBP boosts these ego characteristics. Using a known-groups approach, we did not find differences between mind-body practitioners and non-practitioners regarding self-esteem. Moreover, we found a higher expectation of having a positive influence in the world as only one aspect of communal narcissism. Interestingly, this dimension of communal narcissism also correlated slightly with the participants' reported pro-environmental behavior and climate policy support, both of which can be interpreted as concrete examples of activities that meaningfully contribute to solving a world problem. However, the item wording is rather extreme and intended to go beyond a mere communal orientation (e.g., "I am going to bring peace and justice to the world").

Moreover, we found higher levels of self-compassion and global identity in mind-body practitioners than in non-practitioners. MBP was indirectly related to reported pro-environmental behavior through the higher levels of self-compassion and global identity as well as to climate policy support through higher levels of global identity. Using a larger and more diverse sample in terms of its sociodemographic characteristics, our study replicates the finding that mind-body practitioners exhibit higher levels of global identity, proenvironmental behavior, and climate policy support by Loy and Reese (2019). While Loy and Reese only found significantly higher levels of global self-definition but not of selfinvestment, we found both to be higher among practitioners. However, the effect sizes were stronger for self-definition $(d=0.35)$ than for self-investment $(d=0.24)$ and similar to those found in the study by Loy and Reese (i.e., $d=0.37$ for self-definition, $d=0.20$ for self-investment). Hence, our finding that both were significantly different from non-practitioners might be due to the higher test power of our sample. While the finding of an indirect relation between MBP and pro-environmental engagement through global identity also replicates the results of Loy and Reese (2019), an indirect relation through self-compassion had not been examined previously and thus constitutes a new contribution. However, all indirect relations were small, particularly the one mediated by self-compassion. Global identity appeared to be more relevant in explaining pro-environmental engagement than self-compassion when regarding both simultaneously. Hence, especially our findings regarding self-compassion require replication before drawing firmer conclusions. Moreover, when statistically controlling for gender, we found that females reported stronger global self-investment than males and that MBP practice did not predict global self-investment any longer. Even though females also reported stronger global self-definition, the inclusion of gender as a predictor did not change the finding that MBP was related to global self-definition. These results suggest that MBP might rather strengthen the self-definition component of global identity, which is in line with previous findings (Loy \& Reese, 2019).

Overall, interpreting self-compassion and global identity as components of a quiet ego (Bauer \& Wayment, 2008) and having found them to be more strongly reported by MBP practitioners, we cautiously suggest that MBP might have the potential to contribute more to a quiet ego than to selfenhancement. Moreover, through a quieter ego, MBP might encourage pro-environmental engagement, which can be considered as going beyond mere self-interest. However, these indirect relations in particular need to be replicated before drawing firmer conclusions because they were not stable throughout our analyses.

\section{Limitations and Future Research}

We will first reflect on our measurement approaches. With our study design, we cannot know how participants interpreted the items of the questionnaire, specifically the Communal Narcissism Inventory. Following the argument raised by Lumma et al. (2020), we suspect that mind-body practitioners might have focused on having a positive impact in the world per se rather than on standing out compared to others while answering the respective items. We suggest that future research might assess people's associations while answering the scale by using the think-aloud technique (Fox et al., 2011). Moreover, we deem it worthwhile to examine whether the two-factor structure we found in our sample can be replicated. This might then also inspire a theoretical reflection on different dimensions of communal narcissism which might be differentially related to outcomes—such as pro-environmental engagement in our study.

Future studies could extend our findings by using observational measures instead of self-reports, specifically for pro-environmental behavior (e.g., Lange \& Dewitte, 2019), even though social desirability biases do not seem to be a problematic issue in environmental psychology research (Vesely \& Klöckner, 2020). Nevertheless, observational approaches are useful for reducing common method biases (i.e., spurious correlations between constructs which are assessed with the same method such as self-report questionnaires; Podsakoff et al., 2012). Further valuable approaches are experience sampling or diary methods which assess the variables of interest at several time points in people's natural surroundings (Bolger \& Laurenceau, 2013). Moreover, our quantitative results could be complemented by qualitative findings from in-depth interviews or mixed-method approaches. 
A further limitation of our study is that we do not know the types of meditation or yoga the participants practiced. Future studies should assess this information or explicitly recruit homogeneous groups in order to better compare them to Gebauer et al.'s (2018) participants, who all took part in the same specific courses. Moreover, our study only differentiated between people who currently practice or do not practice MBPs. Future studies could further distinguish between these groups and people who have never had any experience with MBP in the past.

From a theoretical perspective, future studies could include further possible mediating mechanisms such as compassion with others and well-being in order to test our assumption that these might underlie the relation between self-compassion and pro-environmental engagement (Geiger et al., 2019; Pfattheicher et al., 2015). Moreover, studying mindfulness (e.g., Hunecke \& Richter, 2019; see Geiger et al., 2019, for an overview) or nature connectedness (e.g., Aspy \& Proeve, 2017; Barbaro \& Pickett, 2016, see Schutte \& Malouff, 2018, for an overview) could complement the picture.

Due to our cross-sectional and non-experimental design, we cannot establish causality and claim an effect of MBP on the ego components and pro-environmental engagement. Hence, the next step would be to conduct randomized controlled trials examining MBP interventions combined with longitudinal assessments of their outcomes. Longitudinal approaches would also have the advantage of detecting possible nonlinear dynamics. For instance, MBPs might initially boost the ego but then quiet it over time, or vice versa; alternatively, their effects might vary depending on the dosage (see Britton, 2019). Interventional studies could also examine and compare different styles of MBPs to test whether they differentially affect ego components (e.g., with a focus on mindfulness vs. compassion, Aspy \& Proeve, 2017, or with different cognitive mechanisms, Dahl et al., 2015). In order to strengthen the impact of MBPs, it might be helpful to explicitly include ethical topics in MBP classes (Chen \& Jordan, 2020).

Our sample is not representative for the German population as the people in it were highly educated and it included a large proportion of females. In terms of sampling and generalizability, future studies could use random sampling from the general public instead of a research panel. Moreover, samples in different countries could be recruited in order to consider possible cross-cultural differences. Income should be assessed as a further relevant sociodemographic aspect.

Finally, we suggest that future research should aim to further develop a more elaborated and fine-grained definition of the quiet ego which allows differentiated predictions, based on the subcomponents of a quiet ego, rather than studying selected representative constructs as we did. For example, Wayment and colleagues defined a quiet ego as valuing a balance of concerns for self and others and growth of self and others (Bauer \& Wayment, 2008; Wayment \& Bauer, 2018; Wayment et al.,
2015). They provided a categorization of key qualities, namely "inclusive identity, perspective-taking, detached awareness, and growth, and these characteristics facilitate the more general stances of balance and growth toward the self and others" (Wayment et al., 2015, p. 1003). Accordingly, suitable measures should be selected (e.g., the Quiet Ego Scale by Wayment et al., 2015, which assesses the quiet ego as a latent construct represented by the mentioned key qualities). As a next step, research could then also more closely examine the mechanisms through which the effects of MBPs unfold, such as self-other integration (Chiarella et al., 2020), a positive relationship between self and other (Vago \& Silbersweig, 2012), or a dissolution of perceived body boundaries (Dambrun, 2016).

Supplementary Information The online version contains supplementary material available at https://doi.org/10.1007/s12671-021-01823-1.

Author Contribution LSL: collaborated in the design of the study and the data analysis and wrote the paper. AC: collaborated in the design of the study and the data analysis, conducted the data collection, and reviewed and edited the paper. GR: reviewed and edited the paper.

Funding Open Access funding enabled and organized by Projekt DEAL.

\section{Declarations}

Ethics Statement The study was approved by the ethics committee of the University of Koblenz-Landau (\#2020-259) and was performed in accordance with the ethical standards laid down in the 1964 Declaration of Helsinki and its later amendments. The study does not contain details that might disclose the identity of the subjects under study.

Informed Consent Statement All participants gave their informed consent to participate and to the study being published prior to their inclusion in the study.

Conflict of Interest The authors declare no competing interests.

Open Access This article is licensed under a Creative Commons Attribution 4.0 International License, which permits use, sharing, adaptation, distribution and reproduction in any medium or format, as long as you give appropriate credit to the original author(s) and the source, provide a link to the Creative Commons licence, and indicate if changes were made. The images or other third party material in this article are included in the article's Creative Commons licence, unless indicated otherwise in a credit line to the material. If material is not included in the article's Creative Commons licence and your intended use is not permitted by statutory regulation or exceeds the permitted use, you will need to obtain permission directly from the copyright holder. To view a copy of this licence, visit http://creativecommons.org/licenses/by/4.0/.

\section{References}

Allen, J. B., \& Ferrand, J. L. (1999). Environmental locus of control, sympathy, and proenvironmental behavior. Environment and Behavior, 31(3), 338-353. https://doi.org/10.1177/0013916992 1972137 
Aspy, D. J., \& Proeve, M. (2017). Mindfulness and loving-kindness meditation: Effects on connectedness to humanity and to the natural world. Psychological Reports, 120(1), 102-117. https://doi. org/10.1177/0033294116685867

Barbaro, N., \& Pickett, S. M. (2016). Mindfully green: Examining the effect of connectedness to nature on the relationship between mindfulness and engagement in pro-environmental behavior. Personality and Individual Differences, 93, 137-142. https://doi.org/ 10.1016/j.paid.2015.05.026

Bauer, J. J., \& Wayment, H. A. (2008). The psychology of the quiet ego. In H. A. Wayment \& J. J. Bauer (Eds.), Transcending selfinterest: Psychological explorations of the quiet ego (pp. 7-19). American Psychological Association.

Birnie, K., Speca, M., \& Carlson, L. E. (2010). Exploring self-compassion and empathy in the context of mindfulness-based stress reduction (MBSR). Stress and Health, 26(5), 359-371. https:// doi.org/10.1002/smi.1305

Bishop, S. R., Lau, M., Shapiro, S., Carlson, L., Anderson, N. D., Carmody, J., Segal, Z. V., Abbey, S., Speca, M., Velting, D., \& Devins, G. (2004). Mindfulness: A proposed operational definition. Clinical Psychology: Science and Practice, 11(3), 230-241. https://doi.org/10.1093/clipsy.bph077

Bolger, N., \& Laurenceau, J.-P. (2013). Intensive longitudinal methods: An introduction to diary and experience sampling research. Guilford Press.

Bond, T. G., \& Fox, C. M. (2007). Applying the Rasch model: Fundamental measurement in the human sciences ( $2^{\text {nd }}$ ed.). Routledge.

Brito-Pons, G., Campos, D., \& Cebolla, A. (2018). Implicit or explicit compassion? Effects of compassion cultivation training and comparison with mindfulness-based stress reduction. Mindfulness, 9(5), 1494-1508. https://doi.org/10.1007/s12671-018-0898-Z

Britton, W. B. (2019). Can mindfulness be too much of a good thing? The value of a middle way. Current Opinion in Psychology, 28, 159-165. https://doi.org/10.1016/j.copsyc.2018.12.011

Chen, S., \& Jordan, C. H. (2020). Incorporating ethics into brief mindfulness practice: Effects on well-being and prosocial behavior. Mindfulness, 11(1), 18-29. https://doi.org/10.1007/ s12671-018-0915-2

Chiarella, S. G., Makwana, M., Simione, L., Hartkamp, M., Calabrese, L., Raffone, A., \& Srinivasan, N. (2020). Mindfulness meditation weakens attachment to self: Evidence from a self vs other binding task. Mindfulness, 11(10), 2411-2422. https://doi.org/10.1007/ s12671-020-01457-9

Cohen, J. (1992). A power primer. Psychological Bulletin, 112(1), 155-159. https://doi.org/10.1037/0033-2909.112.1.155

von Collani, G., \& Herzberg, P. Y. (2003). Eine revidierte Fassung der deutschsprachigen Skala zum Selbstwertgefühl von Rosenberg [A revised version of the German adaptation of Rosenberg's SelfEsteem Scale]. Zeitschrift Für Differentielle Und Diagnostische Psychologie, 24(1), 3-7. https://doi.org/10.1024//0170-1789. 24.1.3

Dahl, C. J., Lutz, A., \& Davidson, R. J. (2015). Reconstructing and deconstructing the self: Cognitive mechanisms in meditation practice. Trends in Cognitive Sciences, 19(9), 515-523. https://doi.org/ 10.1016/j.tics.2015.07.001

Dambrun, M. (2016). When the dissolution of perceived body boundaries elicits happiness: The effect of selflessness induced by a body scan meditation. Consciousness and Cognition, 46, 89-98. https:// doi.org/10.1016/j.concog.2016.09.013

Fox, M. C., Ericsson, K. A., \& Best, R. (2011). Do procedures for verbal reporting of thinking have to be reactive? A meta-analysis and recommendations for best reporting methods. Psychological Bulletin, 137(2), 316-344. https://doi.org/10.1037/a0021663
Fritsche, I., Barth, M., Jugert, P., Masson, T., \& Reese, G. (2018). A social identity model of pro-environmental action (SIMPEA). Psychological Review, 125(2), 245-269. https://doi.org/10.1037/ rev0000090

Funder, D. C., \& Ozer, D. J. (2019). Evaluating effect size in psychological research: Sense and nonsense. Advances in Methods and Practices in Psychological Science, 2(2), 156-168. https://doi.org/ 10.1177/2515245919847202

Gebauer, J. E., Nehrlich, A. D., Stahlberg, D., Sedikides, C., Hackenschmidt, A., Schick, D., Stegmaier, C. A., Windfelder, C. C., Bruk, A., \& Mander, J. (2018). Mind-body practices and the self: Yoga and meditation do not quiet the ego but instead boost selfenhancement. Psychological Science, 29(8), 1299-1308. https:// doi.org/10.1177/0956797618764621

Gebauer, J. E., Sedikides, C., \& Schrade, A. (2017). Christian selfenhancement. Journal of Personality and Social Psychology, 113(5), 786-809. https://doi.org/10.1037/pspp0000140

Gebauer, J. E., Sedikides, C., Verplanken, B., \& Maio, G. R. (2012). Communal narcissism. Journal of Personality and Social Psychology, 103(5), 854-878. https://doi.org/10.1037/a0029629

Geiger, S. M., Grossman, P., \& Schrader, U. (2019). Mindfulness and sustainability: Correlation or causation? Current Opinion in Psychology, 28, 23-27. https://doi.org/10.1016/j.copsyc.2018. 09.010

Gorvine, M. M., Zaller, N. D., Hudson, H. K., Demers, D., \& Kennedy, L. A. (2019). A naturalistic study of yoga, meditation, self-perceived stress, self-compassion, and mindfulness in college students. Health Psychology and Behavioral Medicine, 7(1), 385-395. https://doi.org/10.1080/21642850.2019.1688154

Gu, J., Baer, R., Cavanagh, K., Kuyken, W., \& Strauss, C. (2020). Development and psychometric properties of the Sussex-Oxford Compassion Scales (SOCS). Assessment, 27(1), 3-20. https://doi. org/10.1177/1073191119860911

Hamer, K., Penczek, M., McFarland, S., Wlodarczyk, A., ŁużniakPiecha, M., Golińska, A., Cadena, L. M., Ibarra, M., Bertin, P., \& Delouvée, S. (2021). Identification with all humanity-A test of the factorial structure and measurement invariance of the scale in five countries. International Journal of Psychology, 56(1), 157-174. https://doi.org/10.1002/ijop.12678

Hunecke, M., \& Richter, N. (2019). Mindfulness, construction of meaning, and sustainable food consumption. Mindfulness, 10(3), 446-458. https://doi.org/10.1007/s12671-018-0986-0

Hupfeld, J., \& Ruffieux, N. (2011). Validierung einer deutschen Version der Self-Compassion Scale (SCS-D) [Validation of a German version of the Self-Compassion Scale (SCS-D)]. Zeitschrift Für Klinische Psychologie Und Psychotherapie, 40(2), 115-123. https://doi.org/10.1026/1616-3443/a000088

Joanes, T. (2019). Personal norms in a globalized world: Norm-activation processes and reduced clothing consumption. Journal of Cleaner Production, 212, 941-949. https://doi.org/10.1016/j.jclep ro.2018.11.191

Kaiser, F. G., \& Byrka, K. (2011). Environmentalism as a trait: Gauging people's prosocial personality in terms of environmental engagement. International Journal of Psychology, 46(1), 71-79. https://doi.org/10.1080/00207594.2010.516830

Kaiser, F. G., \& Wilson, M. (2000). Assessing people's general ecological behavior: A cross-cultural measure. Journal of Applied Social Psychology, 30(5), 952-978. https://doi.org/10.1111/j. 1559-1816.2000.tb02505.x

Kaiser, F. G., \& Wilson, M. (2004). Goal-directed conservation behavior: The specific composition of a general performance. Personality and Individual Differences, 36(7), 1531-1544. https://doi.org/ 10.1016/j.paid.2003.06.003 
Kasser, T. (2017). Living both well and sustainably: A review of the literature, with some reflections on future research, interventions and policy. Philosophical Transactions. Series A, Mathematical, Physical, and Engineering Sciences, 375(2095). https://doi.org/ 10.1098/rsta.2016.0369

Klein, S. A., Nockur, L., \& Reese, G. (2021). Prosociality from the perspective of environmental psychology. Current Opinion in Psychology, 146(80), 30. https://doi.org/10.1016/j.copsyc.2021.09.001

Klöckner, C. A. (2013). A comprehensive model of the psychology of environmental behaviour-A meta-analysis. Global Environmental Change, 23(5), 1028-1038. https://doi.org/10.1016/j.gloen vcha.2013.05.014

Krosnick, J. A., \& Presser, S. (2010). Question and questionnaire design. In P. V. Marsden \& J. D. Wright (Eds.), Handbook of survey research ( $2^{\text {nd }}$ ed., pp. 263-313). Emerald Group Publishing Limited.

Lange, F., \& Dewitte, S. (2019). Measuring pro-environmental behavior: Review and recommendations. Journal of Environmental Psychology, 63, 92-100. https://doi.org/10.1016/j.jenvp.2019.04.009

Leiner, D. J. (2019). Too fast, too straight, too weird: Non-reactive indicators for meaningless data in Internet surveys. Survey Research Methods, 13(3), 229-248. https://doi.org/10.18148/srm/2019. v13i3.7403

Levine, M. (2009). The positive psychology of Buddhism and yoga: Paths to a mature happiness (2nd). Routledge.

Loy, L. S., \& Reese, G. (2019). Hype and hope? Mind-body practice predicts pro-environmental engagement through global identity. Journal of Environmental Psychology, 66, 101340. https://doi.org/ 10.1016/j.jenvp.2019.101340

Loy, L. S., Tröger, J., Prior, P., \& Reese, G. (2021). Global citizens global jet setters? The relation between global identity, sufficiency orientation, travelling, and a socio-ecological transformation of the mobility system. Frontiers in Psychology, 12, 622842. https:// doi.org/10.3389/fpsyg.2021.622842

Lumma, A.-L., Heidenreich, T., \& Michalak, J. (2020). How would the Buddha rate on Rosenberg's Self-Esteem Scale? Mindfulness, 11(2), 521-526. https://doi.org/10.1007/s12671-019-01281-w

Lyubomirsky, S., King, L., \& Diener, E. (2005). The benefits of frequent positive affect: Does happiness lead to success? Psychological Bulletin, 131(6), 803-855. https://doi.org/10.1037/0033-2909. 131.6.803

Marshall, S. L., Parker, P. D., Ciarrochi, J., Sahdra, B., Jackson, C. J., \& Heaven, P. C. L. (2015). Self-compassion protects against the negative effects of low self-esteem: A longitudinal study in a large adolescent sample. Personality and Individual Differences, 81(10), 201-206. https://doi.org/10.1016/j.paid.2014.09.049

McFarland, S., Hackett, J., Hamer, K., Katzarska-Miller, I., Malsch, A., Reese, G., \& Reysen, S. (2019). Global human identification and citizenship: A review of psychological studies. Political Psychology, 40(1), 141-171. https://doi.org/10.1111/pops.12572

McFarland, S., Webb, M., \& Brown, D. (2012). All humanity is my ingroup: A measure and studies of identification with all humanity. Journal of Personality and Social Psychology, 103(5), 830853. https://doi.org/10.1037/a0028724

Naderi, I. (2018). I'm nice, therefore I go green: An investigation of pro-environmentalism in communal narcissists. Journal of Environmental Psychology, 59(6), 54-64. https://doi.org/10.1016/j. jenvp.2018.08.010

Neff, K. D. (2008). Self-compassion: Moving beyond the pitfalls of a separate self-concept. In H. A. Wayment \& J. J. Bauer (Eds.), Transcending self-interest: Psychological explorations of the quiet ego (pp. 95-105). American Psychological Association.

Neff, K. D., \& Germer, C. K. (2013). A pilot study and randomized controlled trial of the mindful self-compassion program. Journal of Clinical Psychology, 69(1), 28-44. https://doi.org/10.1002/jclp. 21923

Otto, S., Pensini, P., Zabel, S., Diaz-Siefer, P., Burnham, E., NavarroVillarroel, C., \& Neaman, A. (2021). The prosocial origin of sustainable behavior: A case study in the ecological domain. Global Environmental Change, 69(2), 102312. https://doi.org/10.1016/j. gloenvcha.2021.102312

Panno, A., Giacomantonio, M., Carrus, G., Maricchiolo, F., Pirchio, S., \& Mannetti, L. (2017). Mindfulness, pro-environmental behavior, and belief in climate change: The mediating role of social dominance. Environment and Behavior, 5(8), 864-888. https://doi.org/ 10.1177/0013916517718887

Pfattheicher, S., Sassenrath, C., \& Schindler, S. (2015). Feelings for the suffering of others and the environment: Compassion fosters proenvironmental tendencies. Environment and Behavior, 48(7), 929-945. https://doi.org/10.1177/0013916515574549

Podsakoff, P. M., MacKenzie, S. B., \& Podsakoff, N. P. (2012). Sources of method bias in social science research and recommendations on how to control it. Annual Review of Psychology, 63, 539-569. https://doi.org/10.1146/annurev-psych-120710-100452

Raes, F., Pommier, E., Neff, K. D., \& van Gucht, D. (2011). Construction and factorial validation of a short form of the SelfCompassion Scale. Clinical Psychology \& Psychotherapy, 18(3), 250-255. https://doi.org/10.1002/cpp.702

Reese, G. (2016). Common human identity and the path to global climate justice. Climatic Change, 134(4), 521-531. https://doi.org/ 10.1007/s10584-015-1548-2

Reese, G., Proch, J., \& Finn, C. (2015). Identification with all humanity: The role of self-definition and self-investment. European Journal of Social Psychology, 45(4), 426-440. https://doi.org/ 10.1002/ejsp.2102

Renger, D., \& Reese, G. (2017). From equality-based respect to environmental activism: Antecedents and consequences of global identity. Political Psychology, 38(5), 867-879. https://doi.org/ 10.1111/pops. 12382

Reysen, S., \& Hackett, J. (2016). Further examination of the factor structure and validity of the Identification with all Humanity Scale. Current Psychology, 35(4), 1-13. https://doi.org/10.1007/ s12144-015-9341-y

Rosenberg, M. (1965). Society and the adolescent self-image. Princeton University Press.

Schoemann, A. M., Boulton, A. J., \& Short, S. D. (2017). Determining power and sample size for simple and complex mediation models. Social Psychological and Personality Science, 8(4), 379-386. https://doi.org/10.1177/1948550617715068

Schutte, N. S., \& Malouff, J. M. (2018). Mindfulness and connectedness to nature: A meta-analytic investigation. Personality and Individual Differences, 127, 10-14. https://doi.org/10.1016/j.paid.2018.01.034

Stanszus, L., Fischer, D., Böhme, T., Frank, P., Fritzsche, J., Geiger, S. M., Harfensteller, J., Grossman, P., \& Schrader, U. (2017). Education for sustainable consumption through mindfulness training: Development of a consumption-specific intervention. Journal of Teacher Education for Sustainability, 19(1), 5-21. https://doi.org/ 10.1515/jtes-2017-0001

Thiermann, U. B., \& Sheate, W. R. (2020). The way forward in mindfulness and sustainability: A critical review and research agenda. Journal of Cognitive Enhancement, 55, 74. https://doi.org/10. 1007/s41465-020-00180-6

Vago, D. R., \& Silbersweig, D. A. (2012). Self-awareness, selfregulation, and self-transcendence (S-ART): A framework for understanding the neurobiological mechanisms of mindfulness. Frontiers in Human Neuroscience, 6, 296. https://doi.org/10.3389/ fnhum.2012.00296 
Vaughan-Johnston, T. I., Jacobson, J. A., Prosserman, A., \& Sanders, E. (2021). Mind-body practices and self-enhancement: Direct replications of Gebauer et al.'s (2018) Experiments 1 and 2. Psychological Science, 32(9), 1510-1521. https://doi.org/10.1177/ 0956797621997366

Vesely, S., \& Klöckner, C. A. (2020). Social desirability in environmental psychology research: Three meta-analyses. Frontiers in Psychology, 11, 1395. https://doi.org/10.3389/fpsyg.2020.01395

Wayment, H. A., \& Bauer, J. J. (2018). The quiet ego: Motives for self-other balance and growth in relation to well-being. Journal of Happiness Studies, 19(3), 881-896. https://doi.org/10.1007/ s10902-017-9848-Z

Wayment, H. A., Bauer, J. J., \& Sylaska, K. (2015). The Quiet Ego Scale: Measuring the compassionate self-identity. Journal of Happiness Studies, 16(4), 999-1033. https://doi.org/10.1007/ s10902-014-9546-Z

Publisher's Note Springer Nature remains neutral with regard to jurisdictional claims in published maps and institutional affiliations. 